Wydanie w otwartym dostępie na licencji CC BY-NC-ND

This is an open access article under the CC BY-NC-ND license

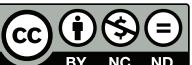

\author{
Aldona Guzik (iD orcid.org/0000-0003-1513-125X \\ Instytut Filozofii i Socjologii \\ Uniwersytet Pedagogiczny \\ aldona.guzik@up.krakow.pl
}

Anna Stolińska (D) orcid.org/0000-0003-0979-011X

Instytut Informatyki

Uniwersytet Pedagogiczny

anna.stolinska@up.krakow.pl

\title{
NIESŁYSZALNI EKSPERCI? ZARZĄDZANIE PERCEPCJĄ WYPOWIEDZI EKSPERCKICH W DOBIE MEDIÓW MULTIMODALNYCH NA PRZYKŁADZIE WYBRANEGO MATERIAŁU Z SERWISU INFORMACYJNEGO - BADANIA PILOTAŻOWE
}

\author{
Abstract \\ IN-AUDIBLE EXPERTS? MANAGING THE PERCEPTION OF EXPERT'S \\ STATEMENTS IN THE ERA OF MULTIMODAL MEDIA, ON THE EXAMPLE OF \\ SELECTED MATERIAL FROM AN INFORMATION SERVICE - PILOT STUDY
}

The article discusses the perception studies of experts commenting political events on television. The aim of the study was to determine to what extent the expert hypothesis works in the era of multimodal communication and information noise. In addition, an attempt was made to identify elements of viewers' attention management, such as: attractors and visual distractors, and to determine the importance of emblems of expertise in qualifying people who speak to this group. Two research techniques were used in the study: eye tracking and surveys, which allowed for comprehensive analysis of multimodal message. Research shows that in the case of such messages, viewers usually use the facecaption-face scheme, with the face being the attractor for both groups - a single person and a crowd. The elements of the background turned out to be distractors, which can be of great importance in the perception of expert statements, since in the media we recently tend to place the expert outside, 
in a dynamic surrounding. At the same time, the analysis showed that expert emblems, e.g. title or clothing, are an indicator of the speaker's belonging to this group. Despite of this, expert statements were considered by the respondents to be aggressive, non-substantive and not adding anything to their knowledge of politics, which supports the recognition of Tom Nichols's thesis about the death of experts and their expertise, and at the same time about the inadequacy of the hypothesis referring to experts in the age of multimodal media.

Keywords: experts, perception, media, multimodality, eye tracking

\section{Wprowadzenie}

Eksperci od zawsze odgrywali szczególną rolę w społeczeństwie. Odwoływanie się do ich opinii było i jest jedną z najważniejszych strategii, jaką kierują się ludzie podczas podejmowania decyzji, co bywa wykorzystywane w celu wywierania wpływu i zapewniania konformizmu w społeczeństwie (por. Cialdini, 2018, s. 225-250). O tym, kto staje się ekspertem, decyduje wiele czynników. Do najważniejszych należą: duża wiedza, charyzma, autorytet lub doświadczenie. Obecnie jednak coraz częściej czynniki te nie są wymagane, a nawet wydają się zbędne². Dzieje się tak (między innymi) w wyniku rozwoju mediów i sposobu, w jaki wpływają one na nasze życie w ponowoczesnym społeczeństwie. Obecny przekaz medialny charakteryzuje multimodalność i komunikacyjny chaos (Hofman, Kępa-Figura, 2018), w którym między innymi znaki pozajęzykowe (tło, ubiór, atrybuty eksperckości, gestykulacja) mogą odciągać uwagę od wypowiedzi ekspertów. Skutkuje to brakiem możliwości ich wpływu na to, o czym i w jaki sposób myślą odbiorcy/widzowie, a zatem podaje $\mathrm{w}$ wątpliwość hipotezę powoływania się na autorytety.

Artykuł wpisuje się w nurt rozważań związanych z postrzeganiem ekspertów i rolą ekspertyz w społeczeństwie wiedzy, ryzyka i mediów multimodalnych. Z jednej strony wydaje się, że szum informacyjny, natłok danych, bodźców wielomodalnych, powoduje, iż ludzie potrzebują wsparcia w selekcji informacji, ich interpretacji i ocenie. $Z$ drugiej jednak przeprowadzone badanie pilotażowe może dawać asumpt do wyciągnięcia wniosku o zmniejszającej się roli ekspertów i ich ekspertyz.

\section{Eksperci w społeczeństwie ponowoczesnym}

Zrozumienie procesu kreowania (się) ekspertów we współczesnym świecie wymaga odwołania się do charakterystyki takiego społeczeństwa i jego aktualnych problemów. Mówiąc o społeczeństwie ponowoczesnym, różnie go określamy:

1 Więcej na ten temat zob. np. w: Kurczewska, 1997; Goćkowski, 1998, s. 48-50; Zakrzewska-Manterys, 2006; Mucha, 2009.

2 Wskazują na to np. Bauman, 1995, 2007; Godzic, 2007; Sartori, 2007; Bourdieu, 2005, 2011 i in. 
społeczeństwo postindustrialne (według Alaina Touraine’a i Daniela Bella na przełomie lat 60. i 70. XX wieku), społeczeństwo wiedzy (termin użyty po raz pierwszy przez Norberta Wienera w 1947 roku, a potem przez Petera Druckera w 1969 roku), społeczeństwo konsumpcyjne (pojęcie użyte np. przez Jeana Baudrillarda w 2006 roku) itp. Często pojawia się również określenie społeczeństwo ryzyka, które wprowadził Ulrich Beck (2002); w społeczeństwie tym podejmowanie decyzji zwłaszcza w złożonej sytuacji - jest dla aktorów społecznych bardzo trudne. O różnicowaniu się współczesnego nam świata i związanym z tym ryzykiem pisał także Niklas Luhmann (1997, s. 29-35) ${ }^{3}$ w swojej koncepcji systemów autopojetycznych, zgodnie z którą cechą immanentną współczesności jest pogłębiające się zróżnicowanie systemu i otoczenia oraz próba jego zredukowania. Tworzenie i konstytuowanie się systemu odbywa się w trakcie procesu komunikacji, który Luhmann rozumie jako niekończący się ciąg wydarzeń, czego konsekwencją jest ujęcie systemu, w tym przede wszystkim systemu społecznego, jako całości dynamicznej, pozostającej w trwałym stadium „stawania się”. Jednocześnie Luhmann, rozwijając swoją teorię systemów społecznych, odwołuje się przede wszystkim do koncepcji Talcotta Parsonsa (1964), dotyczącej komunikacji międzysystemowej oraz systemowych mediów komunikacji, w szczególności zaś do tematu kontyngencji, a zatem nieoznaczonego wyboru potencjalnych możliwości działania.

Jak w tym zróżnicowaniu i wzrastającej specjalizacji ma się odnaleźć aktor społeczny, jak ma rekompensować stan swojej niewiedzy w sytuacji coraz większej złożoności obecnego świata? Wydaje się, że społeczeństwa znalazły antidotum na te problemy - a mianowicie odwołanie się do opinii innych. Tymi innymi przez wieki były: wyrocznie, szamani, kapłani, rady, rodzina, krewni, znajomi i przyjaciele oraz uczeni, czyli - przywódcy opinii (Katz, Lazarsfeld, 1955) ${ }^{4}$. Lista ta jest dość długa i zmienna. Współcześnie zjawisko to uległo jeszcze pogłębieniu, głównie z powodu koncepcji społeczeństwa masowego czy „społeczeństwa wiedzy”. Ta przyjmowana na mocy oczywistości idea pociąga za sobą wiele zobowiązań: od konieczności „uczenia się przez całe życie”, przez stałe dążenie do wyznaczonych odgórnie ideałów, aż po przyjęcie założenia o niekwestionowalności opinii ekspertów. Człowiek

3 O ryzyku we współczesnych społeczeństwach w socjologii pisze się wiele. Zob. np. Bergkamp, 2017; Mythen, 2018 i in.

4 Ich model dwustopniowego przepływu informacji opierał się na założeniu, że treści rozpowszechniane przez środki masowego przekazu nie zawsze docierają do odbiorców bezpośrednio, ale także za pośrednictwem przywódców opinii. Problem polega na rozróżnieniu dwóch procesów: przekazywania (informacji, w tym poglądów, opinii, ocen) oraz wpływania na postawy i świadomość innych ludzi. Katz i Lazarsfeld ujmowali te procesy łącznie, z położeniem akcentu na aspekt oddziaływania za pośrednictwem opinion leaders, w tym też ekspertów.

5 Społeczeństwo wiedzy - model społeczny, w którym główną rolę odgrywa nauka i kapitał intelektualny (Foucault, 1998). Cechuje je m.in.: dominująca rola sektora usług, wzrastająca rola specjalistów i naukowców w strukturze zawodowej, duża rola ekspertów w podejmowaniu decyzji o charakterze indywidualnym, duża rola wiedzy teoretycznej jako podstawy podejmowania decyzji społecznych. 
wychowany w czasach „społeczeństwa wiedzy” ma być, z jednej strony, zdolny do adaptacji $\mathrm{w}$ zmieniających się warunkach, ale $\mathrm{z}$ drugiej ma zachować poczucie sprawstwa i kontroli nad własnym życiem, a także odporność psychiczną w sytuacji życiowego niepowodzenia. W tym właśnie z pomocą przychodzą mu eksperci, którzy - współtworząc syndrom „społeczeństwa wiedzy” - stają się odpowiedzią na niepewne czasy i wszechobecne ryzyko.

Kim zatem jest ekspert? Jak podaje Uniwersalny słownik języka polskiego, ekspert to: „1. specjalista powoływany do wydawania orzeczeń lub opinii w sprawach spornych, wchodzących w zakres jego kompetencji, otrzymujący za swe usługi wynagrodzenie; biegły, rzeczoznawca, 2. osoba uznawana za autorytet w jakiejś dziedzinie, posiadająca doświadczenie, dużą wiedzę o czymś” (https://usjp.pl/ekspert). A zatem liczą się tutaj przede wszystkim twarde kompetencje, takie jak: wiedza, profesjonalizm, specjalizacja i doświadczenie. Mimo to współcześni eksperci pełnią również (albo nawet głównie) funkcję liderów tworzących kanony wiedzy pozajęzykowej, potocznej i dyskursywnej (Nichols, 2017, np. rozdz. VI). W ten sposób kształtują rzeczywistość społeczną, a jednocześnie narzucają jej wizję swoim odbiorcom, wykorzystując do tego kompetencje miękkie, takie jak: komunikatywność, kreatywność, a przede wszystkim medialność. O ich społecznej roli przesądza obecnie nie tylko udział w podsuwaniu społeczeństwu prawomocnych objaśnień dotyczących najróżniejszych obszarów rzeczywistości oraz $\mathrm{w}$ formułowaniu sugestii i zaleceń, jak w każdym z tych obszarów należy postępować, ale także sposób, w jaki to robią: co mówią, w jakim medium (przekaźnik jest przekazem ${ }^{6}$ ), jak mówią/jakim językiem, a nawet - $\mathrm{w}$ dobie mediatyzacji i wizualności - jak wyglądają. Dlatego badania dotyczyły wypowiedzi ekspertów w telewizyjnych serwisach informacyjnych, gdyż jak pisał Pierre Bourdieu (2011, s. 47) ${ }^{7}$ : „Obraz ma szczególną zdolność wytwarzania tego, co krytycy literaccy nazywają efektem rzeczywistości. Telewizja sprawia, że ludzie widzą coś i wierzą w to, co ona pokazuje. To ma duży wpływ na to, o czym ludzie myślą". Czy jednak w dobie wizualności punkt ciężkości nie przesunął się za bardzo w jej stronę? Czy obraz nie przesłania odbiorcy istoty przekazu? Jak podkreśla H.J. Bucher (2015, s. 90): „rozumienie przekazu multimodalnego składa się z różnych rozumień cząstkowych, prowizorycznych, reinterpretacji i nowych interpretacji, które dopiero łącznie tworzą proces interpretowania”. Jeżeli któryś z elementów (słowny czy obrazowy) stanowi źródło kłopotów interpretacyjnych, odbiorca szuka wskazówek w sąsiednim elemencie. Dlatego też próbując odpowiedzieć na te pytania wykorzystano badania eye-trackingowe i ankietowe, które pomogły ustalić, co przykuwa uwagę odbiorców serwisów informacyjnych i wypowiadających się w nich ekspertów. Obie techniki wpisują się w obszar multimodalnych badań mediów, które pozwalają na wieloaspektowe podejście do komunikacji. Na czym ono polega? Według Ricka Tedemy (2013, s. 217) badanie multimodalne

6 Zob. McLuhan, 2004.

7 Późniejsze przykładowe badania nad telewizją zob.: Rose, 2012; Jewitt, van Leeuwen, 2013 lub Rose, 2015. 
powinno uwzględniać wszystkie systemy semiotyczne współtworzące komunikat, przy czym systemy te należałoby traktować nie w izolacji, lecz we wzajemnych powiązaniach (przy uwzględnieniu zarówno relacji intramodalnych, jak i intermodalnych), obserwując, jak rozmaite środki semiotyczne wzajemnie się kontekstualizują. W dodatku ustalanie zależności między współpracującymi systemami powinno uwzględniać i taką możliwość, że w niektórych przekazach znaki językowe nie muszą być najważniejszym kodem sensotwórczym i mogą być zastępowane/lub wypierane przez obraz, co stanowiłoby przesłankę do stawiania hipotez podobnych do tych formułowanych przez Toma Nicholsa (2017), który wieszczy śmierć ekspertów i ekspertyzy w dobie nowych mediów.

\section{Metodologia}

Celem badań było zdiagnozowanie ${ }^{8}, \mathrm{w}$ jakim stopniu wypowiedzi ekspertów i oni sami (jako postaci prezentowane w mediach) skupiają uwagę słuchaczy, oraz znalezienie odpowiedzi na pytania:

1. Czy istnieje schemat (wzorzec) kierowania uwagi wzrokowej podczas wypowiedzi osób z prezentowanego nagrania?

2. Które obszary (elementy sceny wizualnej) skupiały najdłużej uwagę wzrokową?

3. Które elementy znajdujące się w tle można uznać za dystraktory?

4. Czy atrybuty ekspertów (rozumiane jako elementy wyróżniające, typu: czerwony krawat, toga, kapelusz, biało-czerwony pasek) skupiały na sobie wzrok badanych?

Dodatkowo dokonano analizy percepcji przez uczestników badań wypowiedzi werbalnych ekspertów i podjęto próbę odpowiedzi na pytanie badawcze:

5. Które informacje przekazywane przez ekspertów zapamiętali respondenci i jak je oceniali?

W badaniach wykorzystano dwie integralne techniki badań: ankietę i okulografię (eye tracking). Rejestrację ruchów gałek ocznych wykorzystano w celu dokonania pogłębionej analizy percepcji przez odbiorców wypowiedzi ekspertów komentujących wydarzenia polityczne. Wydaje się, że taka decyzja jest zasadna, zważywszy na to, że uwaga wzrokowa jest jednym z elementów struktury odpowiedzialnej za selekcję informacji i zapobieganie przeładowaniu systemu poznawczego przez nadmiar percepowanych danych (Nęcka, Orzechowski, Szymura, 2008). Gdy prezentowanym bodźcem wizualnym są ludzie, uwaga wzrokowa skupia się na ich twarzach. Taki mechanizm jest uwarunkowany społecznie - twarze dostarczają

8 Badania miały charakter pilotażowy, zostały przeprowadzone na jednym materiale pochodzącym z jednego serwisu informacyjnego, a zatem wyciągane wnioski są jedynie przyczynkiem do przeprowadzenia szerszych badań w przyszłości. 
wielu wartościowych informacji, takich jak na przykład tożsamość czy emocje (Min, Zhai, Gu, 2015). Kiedy oglądana osoba mówi, eksploracja pola oprócz oczu może obejmować również usta, przy czym kierowanie uwagi wzrokowej jest uwarunkowane tematyką wypowiedzi, jej nasyceniem emocjonalnym lub wysiłkiem poznawczym wynikającym z potrzeby zrozumienia wypowiedzi (Eisenbarth, Alpers, 2011).

Problem badawczy koncentruje się wokół multiplikacji danych przekazywanych $\mathrm{w}$ trakcie wypowiedzi eksperckich ich odbiorcom. Przedmiotem badań był proces percepcji dźwięku i obrazu podczas wypowiedzi ekspertów w serwisie informacyjnym. Znalezienie odpowiedzi na pytania badawcze wymagało sięgnięcia po technikę umożliwiającą podjęcie próby wnioskowania o procesach poznawczych - w szczególności o uwadze wzrokowej, a za taką uważa się okulografię (Frutos-Pascual, Garcia-Zapirain, 2015).

Eye tracking umożliwia rejestrację ruchów oczu, spośród których dwa podstawowe - fiksacje i sakkady - pozwalają na śledzenie tak zwanych ścieżek wzroku. Fiksacje są względnie stabilnym zatrzymaniem wzroku, podczas którego zachodzi pobieranie informacji wizualnych. Sakkady to ruchy przenoszące położenie oczu tak, by możliwa była percepcja bodźca przez najbardziej wrażliwą część siatkówki - celu pobrania informacji. Sakkady są zatem interwałem pomiędzy fiksacjami (Hessels i in., 2018). Ścieżki wzroku są wyznaczane przez sakkady (wizualizowane jako linie) i fiksacje (koła, których promień jest proporcjonalny do czasu względnie trwałego zatrzymania wzroku) - ich analiza dostarczy informacji, które będą pomocne w udzieleniu odpowiedzi na pytania badawcze. Ilustracja 1 przedstawia fragment przykładowej ścieżki wzrokowej stanowiącej przedmiot analizy.

W eksperymencie przeprowadzonym w okresie: wrzesień-grudzień 2019 roku wzięło udział 36 osób $^{9}$, 16 kobiet i 20 mężczyzn w wieku 22-65 lat; byli to studenci i pracownicy Uniwersytetu Pedagogicznego w Krakowie. Dobór próby był celowy z kryterium wejścia określonym wiekiem i kryterium różnicującym ze względu na płeć i zainteresowanie lub brak zainteresowania polityką. Wzrok badanych był normalny lub skorygowany do normalnego. Uczestnicy eksperymentu zostali poinformowani, iż uczestnictwo $\mathrm{w}$ nim nie będzie wiązać się z pytaniami na temat ich poglądów politycznych, a ich odpowiedzi pozostaną anonimowe. Wszyscy badani wyrazili zgodę na udział w eksperymencie. Badania przeprowadzono w laboratorium eye-trackingowym Uniwersytetu Pedagogicznego z izolacją akustyczną i w stałych warunkach oświetleniowych. Zastosowano eye-tracker firmy Senso Motoric Instruments i ViewX $\mathrm{X}^{\mathrm{sw}} \mathrm{Hi}$-Speed500/1250 rejestrujący strumień danych z rozdzielczością czasową $500 \mathrm{~Hz}$. Wyniki opracowano z wykorzystaniem oprogramowania SMI BeGazeTM 2.4.

9 Dane pomiarowe jednej osoby odrzucono ze względów technicznych (doszło do rozkalibrowania urządzenia w trakcie eksperymentu - badany oznaczony symbolem „p33”), a do dalszej analizy zakwalifikowano 35 przypadków. 


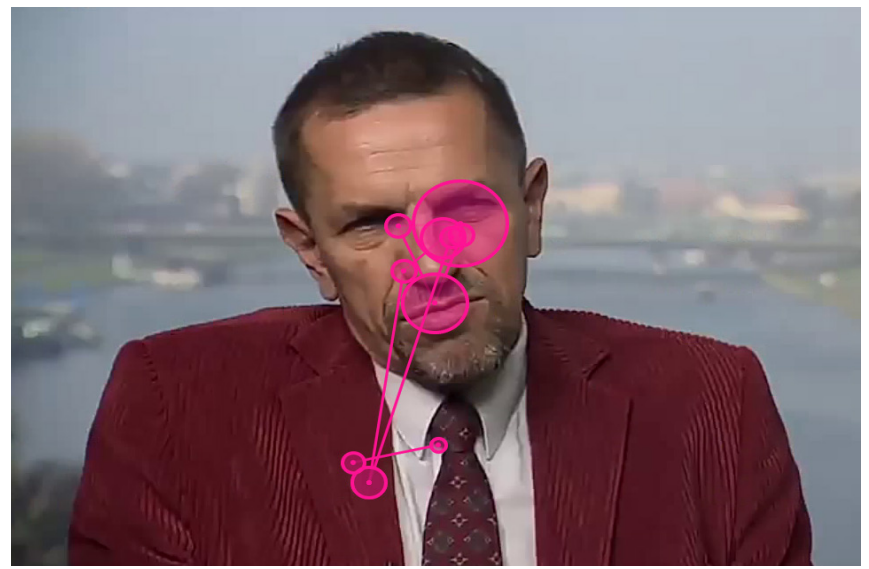

Ilustracja 1. Przykładowa ścieżka wzrokowa badanego

Źródło: opracowanie własne.

Badani oglądali fragment serwisu informacyjnego, którego długość wynosiła 3 minuty 46 sekund ${ }^{10}$. Nagranie zostało zrealizowane $w$ roku poprzedzającym badania, w okresie, w którym - w opinii autorek badań - nie występowały szczególnie kontrowersyjne ani angażujące odbiorców wydarzenia. Zostało ono dobrane w taki sposób, aby były w nim prezentowane wypowiedzi ekspertów o zróżnicowanym wieku, wyglądzie (ubiorze) oraz wypowiadających w różnych miejscach, na tle różnych scen wizualnych (animowanych - z poruszającymi się w tle ludźmi czy samochodami lub statycznych) i dotyczył wątku wyników wyborów samorządowych, gdyż polityka jest tematem, którym wszyscy się interesują i zazwyczaj mają w tym zakresie wiedzę i poglądy. Nie stanowi on natomiast podstaw do wyciągania uogólnionych wniosków $\mathrm{z}$ uwagi na pilotażowy charakter badań, w tym wybór tylko jednego medium. Wybrany film prezentował wypowiedzi 9 ekspertów, przy czym $3 \mathrm{z}$ nich wypowiadało się dwukrotnie, po krótkich przerwach, $\mathrm{w}$ których przedstawiano sceny z konwencji wyborczych lub wystąpienia innych osób. Badani wysłuchali 12 wypowiedzi „eksperckich”, przeplatanych wypowiedziami nie-ekspertów, na przykład polityków. Ponadto w trakcie wypowiedzi ekspertów i komentarza redaktora pojawiały się na dole ekranu paski informujące o imieniu i nazwisku osoby wypowiadającej się oraz jej zawodzie i/lub zajmowanym stanowisku. Po badaniu okulografem każdy z uczestników eksperymentu wypełniał kwestionariusz ankiety, składający się z 11 pytań, które dotyczyły zapamiętanych nazwisk ekspertów, treści

10 Audycja dostępna pod adresem: https://fakty.tvn24.pl/ogladaj-online,60/wyborysamorzadowe-potwierdzily-podzial-na-dwa-obozy-polityczne,878671.html (dostęp: 6.05.2020). 
(zagadnień) przez nich omawianych, słów kluczowych, zapamiętanych elementów scen wizualnych czy też emblematów świadczących o wykonywanym zawodzie lub pełnionej funkcji ${ }^{11}$.

\section{Wyniki badań, ich analiza i dyskusja}

Do analizy danych pomiarowych zastosowano analizę jakościową. W tym celu wygenerowano wizualizacje ścieżek wzroku dla wszystkich badanych osób i prześledzono kolejność fiksacji na poszczególnych elementach sceny wizualnej. Działania te pozwoliły na podjęcie próby odpowiedzi na te pytania badawcze, które odnoszą się bezpośrednio do zagadnień związanych z zarządzaniem uwagą wzrokową.

W przypadku pytania pierwszego: (1) czy istnieje schemat (wzorzec) kierowania uwagi wzrokowej podczas wypowiedzi osób $z$ prezentowanego nagrania?, szczegółowy przegląd danych pozwala na sformułowanie spostrzeżenia, że spośród 35 analizowanych przypadków 33 osoby oglądały wypowiedzi ekspertów zgodnie ze schematem: najpierw następowała obserwacja twarzy, następnie w chwili, gdy pokazywał się pasek, na którym zamieszczono prezentację eksperta, wzrok był kierowany na niego, a potem uwagę wizualną badanych ponownie skupiała twarz wypowiadającego się. Wśród 420 analizowanych konfiguracji (p[n] * EKSP[m], gdzie $\mathrm{n}=35$ uczestników badań, $\mathrm{m}=12$ wypowiedzi eksperckich), 117 odbywało się według wzorca: fiksacje na twarzy, zapoznanie się z treścią wyświetlaną na pojawiającym się pasku, a następnie powrót na twarz eksperta. Kolejne 20 to schemat: twarz, pasek, twarz, pasek, twarz, a 3 inne ścieżki, to fiksacje na twarzy, podpisie, twarzy i ostatnie zarejestrowane na podpisie. Można zauważyć, że w 33,3\% (140) przypadków wzorzec kierowania uwagi był niezakłócony, czyli skoncentrowany na atraktorach (twarz, pasek $\mathrm{z}$ informacją tekstową). W pozostałych przypadkach u uczestników badań można było zaobserwować zatrzymania wzroku na innych elementach scen - na przykład na ubiorze ekspertów lub bodźcach znajdujących się w tle.

Tylko $\mathrm{w}$ dwóch przypadkach uczestnicy badań mieli odmienny schemat kierowania uwagi wzrokowej - ich fiksacje były w zdecydowanej większości przypadków (p08: 9 spośród 12 ekspertów, p14: 11 spośród 12 osób wypowiadających się) skoncentrowane na twarzach ekspertów. $Z$ analizy odpowiedzi udzielanych przez uczestników eksperymentu na pytania kwestionariuszowe wynika, iż badany p08 był mężczyzną, który zapamiętał 4 nazwiska wypowiadających się ekspertów, ponadto ocenił ich narrację jako negatywną i niemerytoryczną, nacechowaną takimi

11 Taki dobór pytań miał na celu rozpoznanie wagi różnic w zapamiętywaniu przez badanych przekazu słownego i wizualnego przekazywanych treści. Jest to poparte badaniami i wnioskami, zob. np. Basil, 1994a, 1994b lub Francuz, Cwalina, 1999 i in. Badania te wskazują, iż obraz skupia uwagę na cechach powierzchownych, nadając znaczenie kategoriom społecznym i etykietowaniu. Krótki czas przekazywania informacji sprzyja uproszczonemu myśleniu, utrudnia koncentrację na treści argumentów - ważniejsza staje się ich liczba, a nie jakość czy osoba nadawcy. 
słowami jak: wybory, podział, agresywne nastawienie wobec siebie dominujących partii. W wizualnej ocenie ekspertów dominowało - w jego ocenie - ich dobre, schludne ubranie, zauważalny język ciała i stosowane przez nich kalki językowe, które późnej mogą być powielane przez odbiorców. Jako emblematy eksperckości wymienił ubranie (garnitur, toga). Z kolei badanym p14 była kobieta, która zapamiętała nazwiska 6 wypowiadających się ekspertów, ich narracja została przez nią oceniona jako neutralna i merytoryczna, nacechowana takimi słowami, jak: wybory, podział na Polskę A i B, walka o władzę. W wizualnej ocenie ekspertów dominowały szczegóły typu: uśmiech czy czerwony krawat. Jako emblematy eksperckości wymieniła ubranie (garnitur), ale także podpisy zawierające informacje o prezentowanych ekspertach.

Wynika z tego, że percepcja bodźców wizualnych i dźwiękowych była uwarunkowana emocjami - badani odczytywali je wprawdzie odmiennie, ale zaangażowanie w ich rozpoznawanie kierowało uwagę badanych głównie na twarze ekspertów, co potwierdzają wyniki dotychczas przeprowadzanych badań (Eisenbarth, Alpers, 2011).

Ilustracja 2 przedstawia focus maps dla wszystkich osób badanych i ekspertów w różnych momentach ich oglądania. Obrazy te stanowią wizualizację koncentracji uwagi wzrokowej (elementy sceny wizualnej, na których badany zatrzymywał wzrok, są widoczne, rozjaśnione, pozostałe obszary zaś są zaciemnione). Niektóre ilustracje pokazują koncentrację uwagi tylko na twarzach, inne pozwalają zauważyć, że w tym samym czasie część badanych oglądała twarz wypowiadającej się osoby, inni natomiast czytali tekst umieszczony na pasku.
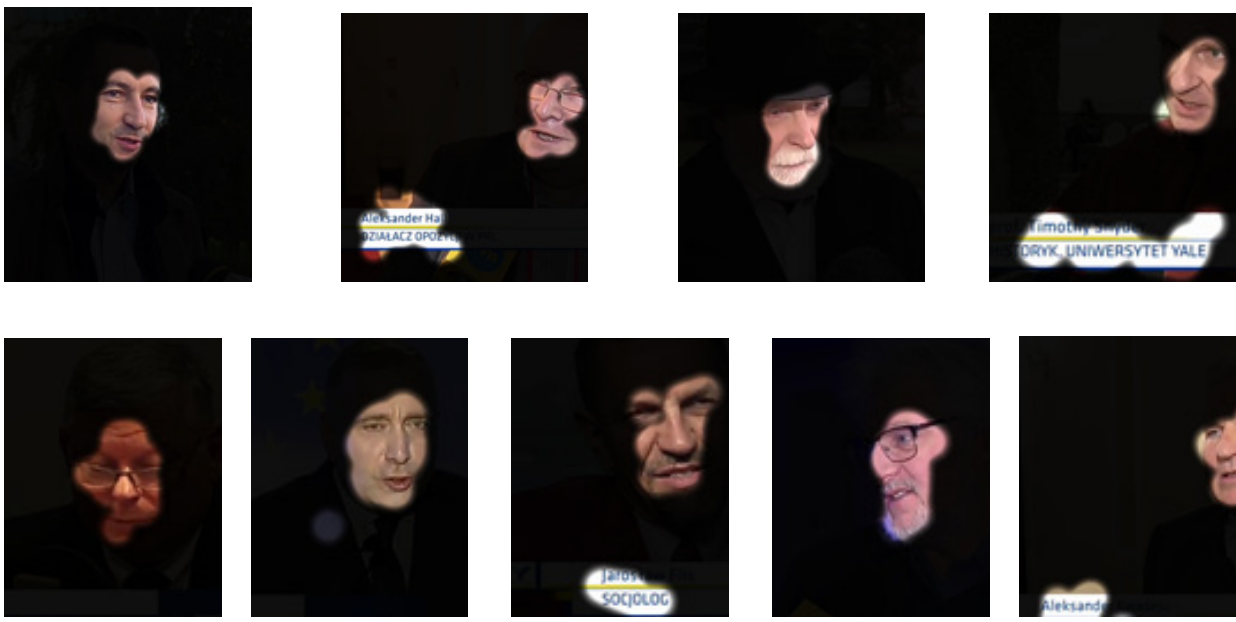

Ilustracja 2. Focus maps

Źródło: opracowanie własne. 
Kolejne pytanie badawcze wymagające odpowiedzi było następujące: (2) które obszary (elementy sceny wizualnej) skupiały najdtużej uwage wzrokowa? Ustalono, że spośród wszystkich elementów sceny wizualnej, które oglądali badani, najdłużej uwagę wzrokową skupiały twarze ekspertów. Potwierdzają to mapy cieplne (heat maps), w których kolory odzwierciedlają rozkład uwagi w czasie. Im bardziej czerwony kolor, tym więcej czasu wzrok spoczywał na danym elemencie. Potwierdza to jednocześnie zaobserwowany schemat kierowania uwagi badanych: twarz - pasek - twarz.

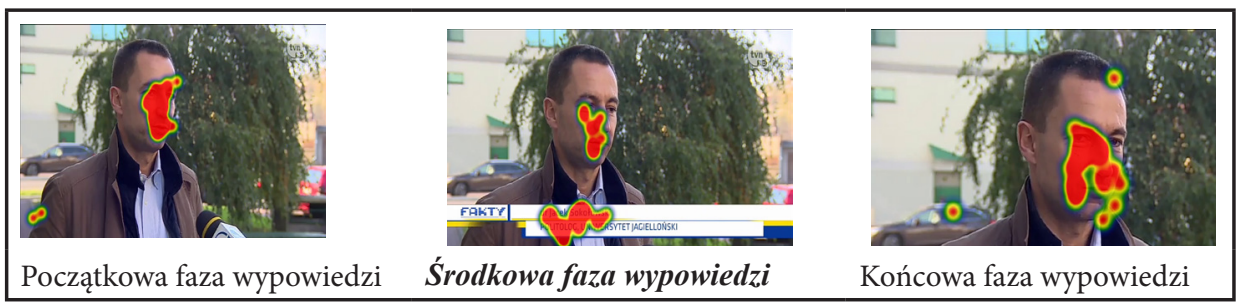

Ilustracja 3. Heat maps obrazujące fazy koncentracji uwagi podczas wypowiedzi (wzorzec kierowania uwagi)

Źródło: opracowanie własne.

Również w przypadku, gdy badani mieli możliwość oglądania tłumu, twarze stanowiły atraktor, a wśród nich te, o których można powiedzieć, że są rozpoznawalne (liderzy największych w Polsce partii politycznych), co prezentuje ilustracja 4.
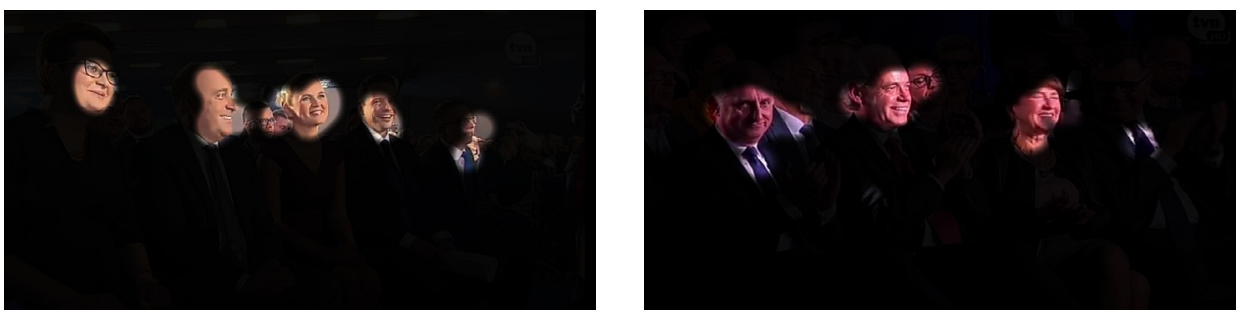

Ilustracja 4. Atraktory w tłumie

Źródło: opracowanie własne.

Trzecie pytanie badawcze dotyczyło dystraktorów, za które uznano elementy sceny wizualnej (bodźce), skupiające uwagę wzrokową i niezwiązane treściowo 
z prezentowanym uczestnikom badań materiałem audiowizualnym. Ilustracja 5 przedstawia przykładowe dystraktory.
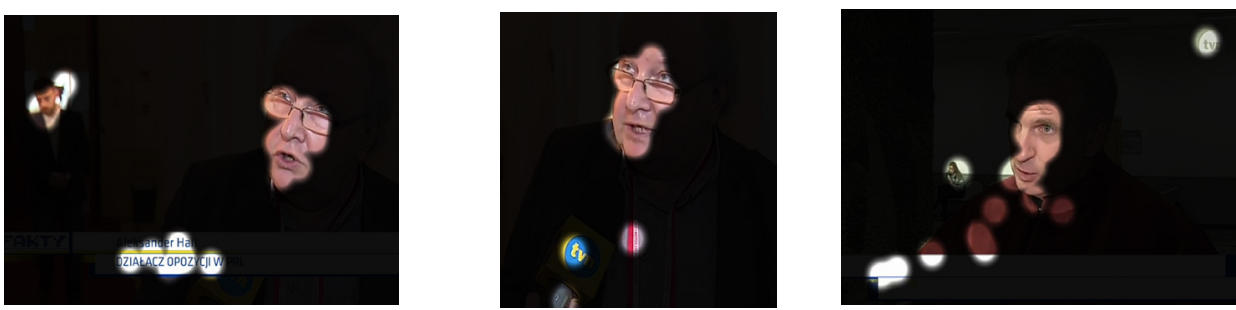

Ilustracja 5. Przykładowe dystraktory

Źródło: opracowanie własne.

Na pytanie o to, (3) które elementy znajdujące się $w$ tle można uznać za dystraktory?, analiza 420 konfiguracji pozwoliła ustalić, że są nimi między innymi drzewo, most, mozaika na ścianie, samochód, mikrofon, logotyp stacji telewizyjnej umieszczony w prawym górnym rogu ekranu lub na mikrofonie, napis „Fakty” czy też ludzie znajdujący się w tle. Prezentacji niemal wszystkich ekspertów towarzyszyły czynniki rozpraszające, gdyż nie występowali oni w statycznym otoczeniu. Obecnie jest to dominujący w mediach sposób prezentowania ekspertów. Wydaje się, że neutralne tło w mniejszym stopniu odciągałoby zarówno uwagę wizualną, jak i skupienie widzów na treści. Mimo to stwierdzenie, czy dynamika scen znajdujących się w tle wypowiadających się osób wpływa na zmniejszenie koncentracji uwagi na treści komunikatów słownych (dźwiękowych), wymaga pogłębionych badań. Należy jednak zauważyć, że spośród badanych tylko dwie osoby nie zwróciły uwagi na otoczenie ekspertów, pozostali wymienili w ankiecie po kilka elementów z otoczenia, które zapamiętali po obejrzeniu nagrania.

W dalszej kolejności analizowano, (4) czy atrybuty ekspertów (rozumiane jako elementy wyróżniajace, typu: czerwony krawat, toga, kapelusz, biało-czerwony pasek identyfikatora) skupiały na sobie dłużej wzrok badanych? Ustalono, że to, jak ubrani są eksperci, zwróciło uwagę wzrokową 31 uczestników badań. Fiksacje na okryciu wierzchnim wystąpiły najczęściej w przypadku EKSP1 i EKSP4 (odpowiednio 20 i 23 badanych spojrzało na ich ubranie). Można założyć, że EKSP1 skupiał uwagę ze względu na efekt pierwszeństwa, drugi natomiast (EKSP4) ze względu na specyficzny ubiór - swoisty emblemat (toga profesorska) i tytuł naukowy.

Dopełnieniem badań eye-trackingowych były badania ankietowe polegające na tym, że badani po obejrzeniu filmu $\mathrm{z}$ nagraniem otrzymywali kwestionariusz ankiety, zawierający 11 pytań odnoszących się do tego, co obejrzeli. Celem tej części procedury badawczej było ustalenie, kogo i co zapamiętali uczestnicy eksperymentu (które bodźce werbalne i wizualne), a w szczególności znalezienie odpowiedzi na 
ostatnie pytanie badawcze: (5) jakie informacje przekazywane przez ekspertów zapamiętali respondenci i jak je oceniali?

Dane empiryczne wskazują, iż na 9 wypowiadających się ekspertów badani najczęściej zapamiętywali i wymieniali nazwiska dwóch z nich - tak wskazało 9 badanych. Tylko 4 uczestników badań (wszyscy to mężczyźni) zapamiętało nazwiska siedmiu wypowiadających się ekspertów. Nie było ani jednej osoby, która wskazałaby wszystkie nazwiska ekspertów, z kolei 3 osoby nie potrafiły podać ani jednego nazwiska eksperta. Oprócz liczby zapamiętanych nazwisk w tym pytaniu można także przeanalizować typy zapamiętanych ekspertów. Badani wymienili przede wszystkim nazwiska polityków: Aleksandra Kwaśniewskiego (EKSP9), Grzegorza Schetyny (EKSP6), Jarosława Kaczyńskiego (mimo że się nie wypowiadał, lecz był tylko pokazany jako tło wypowiedzi dziennikarskiej) i Aleksandra Halla (EKSP2). Najczęściej wymieniano nazwisko Aleksandra Kwaśniewskiego, ale był to prawdopodobnie skutek tego, że jego wypowiedź prezentowano jako ostatnią, a zatem mamy tutaj do czynienia z tzw. efektem świeżości ${ }^{12}$. Za wiarygodnych ekspertów badani uznali naukowców: dr. hab. Jarosława Flisa (EKSP7) i prof. Timothy'ego Snydera - EKSP4 (których wymienili odpowiednio: 12 i 6 razy) oraz dr. Jacka Sokołowskiego - EKSP1 (3 razy) i prof. dr. hab. Radosława Markowskiego - EKSP8 (1 wskazanie). W większości przypadków badani przy wymienianiu nazwisk nie podawali stopni i tytułów naukowych, wyjątkiem był prof. Timothy Snyder, przy którym zawsze podawano tytuł naukowy. Ponadto wystąpił on w todze, którą uznajemy za oznakę/emblemat eksperta, co może go dodatkowo uwiarygadniać w tej roli. Można zatem wnioskować, że posiadanie tytułu naukowego cieszy się estymą i zaufaniem odbiorców - i tylko w tym przypadku można byłoby mówić o wpływie autorytetów (wymaga to jednak pogłębionych badań).

Mniej problemów mieli badani ze wskazaniem obszaru tematycznego materiału, który został im przedstawiony. Większość (26 osób) opisywała go szeroko: polityka, wybory, podziały polityczne, wyniki wyborów. Tylko 9 osób zawęziło go do wyborów samorządowych, co może być rezultatem tego, że choć rzeczywiście film odnosił się bezpośrednio do nich, to wypowiadający się eksperci oceniali je z szerszej perspektywy, tworząc również prognozy na przyszłość.

Ciekawie prezentują się także wyniki kolejnego pytania, dotyczącego słów zapamiętanych z wypowiedzi ekspertów (tzw. słów kluczy). Można je podzielić na pozytywne (tylko 2): demokracja i koalicja, neutralne: wybory, wyniki, przyszłość, partie polityczne, elektorat, analiza wyników wyborów, poparcie, zdolności koalicyjne i negatywne: PiS-owska szarańcza, mirabelki, podziały, Polska A i B, plemiona, konflikt, wojna między partiami, linia podziału, wygrani i przegrani, walka o władzę, utrzymanie przewagi, PiS i anty-PiS, nienawiść, wyplewić, podzielona Polska, język wrogości, obozy polityczne. Można zatem stwierdzić, iż w wypowiedziach

12 Chodzi o zapamiętywanie informacji i ich oddziaływanie na ludzi. Lepiej zapamiętujemy (i bardziej oddziałują na nas) informacje, które dotarły do nas jako pierwsze, na początku - to tzw. efekt pierwszeństwa, a także te na końcu - tak działa efekt świeżości (por. Wojciszke, 2002, s. 122, 232-234). 
eksperckich dominowała narracja negatywna, wręcz wojenna, zważywszy na zapamiętane słowa klucze, która wzmacniała istniejące spory polityczne (co widać również po dychotomicznym zestawieniu polityków w roli ekspertów). Wynika to także z analizy odpowiedzi badanych, którzy - zapytani o ocenę przesłania wypowiedzi eksperckich - w 16 przypadkach określili je jako negatywne, wręcz agresywne, w 10 jako neutralne i tylko jedna osoba oceniła je pozytywnie, a 8 badanych miało problem z jednoznaczną ich oceną (odpowiedź: trudno powiedzieć).

Interesująco przedstawiają się także odpowiedzi uczestników badań na pytania dotyczące samych ekspertów. Tylko jedna trzecia badanych (13 osób) określiła ich wypowiedzi jako merytoryczne, jedna trzecia miała problem $\mathrm{z}$ ich oceną (odpowiedź: trudno powiedzieć), pozostali natomiast (9 osób) określili ich wypowiedzi jako niemerytoryczne. A zatem ponad połowa badanych stwierdziła, że komentarze ekspertów nie wniosły nic konkretnego do ich wiedzy na temat polskiej polityki. Czy zatem wygląd i otoczenie mogły być w tym przypadku skutecznym dystraktorem percepcji przekazu ekspertów? ${ }^{13} \mathrm{~W}$ tym celu zapytano badanych o zapamiętane znaki szczególne ekspertów i emblematy ich eksperckości oraz o elementy ich otoczenia. Tylko 3 badanych nie zapamiętało żadnych znaków szczególnych. Pozostali wymieniali takie elementy, jak: garnitur/dobre ubranie, toga, kapelusz, okulary, a więc łatwo zauważalne elementy ubioru, ale były też te bardziej szczegółowe, na przykład: siwe włosy, uśmiech, czerwony krawat czy czerwony garnitur, błyszcząca cera, język ciała, zapudrowane znamię na policzku (p13, mężczyzna), błyszczący fragment twarzy pod nosem (p25, mężczyzna), identyfikatory, zagraniczny akcent. Jako emblematy eksperckości badani wskazali: ubiór (garnitur, garsonka), togę, podpis/pasek z podanym imieniem, nazwiskiem i stopniem, tytułem naukowym oraz identyfikator. Także różne elementy otoczenia ekspertów były często wymieniane przez badanych, na przykład studio, panorama Krakowa, inne osoby w tle, flagi, przejeżdżające samochody, budynki państwowe, urzędy, studia wyborcze, tłum ludzi, logo stacji, podpisy itp. Tylko dwie osoby nie zwróciły uwagi na elementy otoczenia/tła. W obu przypadkach były to kobiety (p15 i p22), które jednocześnie nie pamiętały nazwisk ekspertów, znaków szczególnych ani emblematów eksperckości.

Z wielu badań psychologicznych wynika, że kobiety przetwarzają bodźce wzrokowe w taki sam sposób jak mężczyźni ${ }^{14}$. W naszym badaniu wzięło udział 15 kobiet

13 Pytanie to ma oparcie w koncepcji kultury obrazu (wizualnej) - Umberto Eco, Susan Sontag, Piotr Sztompka, Roland Barthes, Jean Baudrillard, John Grady, Luc Pauwels, Sarah Pink i wielu innych - oraz zwrotu ikonograficznego, np. Boehm, Mitchell, 2009; Jenks, 1995, s. 1-25; Olechnicki, 2016, s. 6-16; Porębski, 1972, s. 18. Co łączy tych znakomitych badaczy? To, że zdają sobie sprawę, iż zrozumienie współczesnego świata, badanie życia społecznego, wnikanie w tkankę społecznej rzeczywistości i odkrywanie społecznego DNA wymaga uwzględnienia perspektywy wizualnej. Nurt ten zapoczątkował w 1921 roku Georg Simmel, który zauważył, że oko ludzkie odgrywa wyjątkową rolę w socjologii.

14 Tezę tę potwierdzają wyniki opublikowanej dwa lata temu (2018) na łamach „Proceedings of the National Academy of Sciences" metaanalizy, w trakcie której doktor Ekaterina Mitricheva wraz 
i 20 mężczyzn. Czy zatem płeć może mieć znaczenie w percepcji przekazów audiowizualnych? Jak się okazuje, to kobiety nie pamiętały nazwisk ekspertów i słów użytych przez nich w trakcie wypowiedzi, nie zauważyły też żadnych znaków szczególnych ani nie potrafiły wymienić emblematów eksperckości. Natomiast mężczyźni, którzy zapamiętali najwięcej nazwisk (7 na 9 wypowiadających się ekspertów) zapamiętali też najwięcej słów kluczy, które były bardzo szczegółowe, na przykład wartości procentowe, wyniki wyborów, PiS-owska szarańcza, mirabelki itp. Jednocześnie podali oni najwięcej szczegółów wizualnych dotyczących obejrzanego materiału, takich jak: Flis - wąsy, Kwaśniewski - zapudrowane znamię na lewym od strony oglądającego policzku, historyk prof. Snyder - zadbany (p13), Hall - błyszczący fragment twarzy pod nosem (p25) i siwe włosy, otyłośc; jeden z komentatorów był podpisany jako działacz opozycji w PRL, jeden był obcokrajowcem (p37). Elementy otoczenia również zostały przez nich szczegółowo opisane: park, plakaty wyborcze, sala PE, korytarz, niebieskie tło (p13), Kwaśniewski - blisko ściany, Snyder - na korytarzu (może też widoczne schody), Suski - przy stole, Schetyna - w hali pełnej ludzi, Flis - panorama Krakowa, za Hallem z lewej w tle ludzie (p25) oraz korytarz z krzesłami, konwencja partii, w otoczeniu dziennikarzy, przechodzący między ludźmi, w lokalu wyborczym (p37). Podali także główne emblematy ich eksperckości: ubiór (garnitur, biała koszula z kołnierzykiem), toga, identyfikator, podpisy zawierające imię, nazwisko i stopień lub tytuł naukowy. Nie można jednak na podstawie tych wyników sformułować wniosku, że płeć ma wpływ na percepcję wypowiedzi eksperckich, ponieważ takie spostrzeżenie wymagałoby przeprowadzenia badań na grupie badawczej o większej liczebności oraz bardziej zróżnicowanym materiale badawczym. $\mathrm{Z}$ naszych badań wynika tylko, że w analizowanej próbie to mężczyźni byli bardziej uważni zarówno pod względem werbalnych, jak i pozawerbalnych przekazów zawartych w obejrzanym filmie.

\section{Wnioski i podsumowanie}

Jak wynika z naszych badań pilotażowych, percepcja bodźców wizualnych i dźwiękowych była uwarunkowana emocjami - badani odczytywali je wprawdzie odmiennie, ale zaangażowanie $\mathrm{w}$ ich rozpoznawanie kierowało uwagę badanych głównie na twarze ekspertów, z przeważającym wzorcem: twarz - pasek - twarz. Dystraktorem uwagi badanych było ruchome tło/otoczenie ekspertów prezentowanych w materiale filmowym, atraktorami natomiast były twarze i informacje tekstowe

\footnotetext{
ze współpracownikami z Instytutu Maxa Plancka w Tybindze analizowała 61 badań wykorzystujących technikę funkcjonalnego rezonansu w ocenie aktywności mózgu podczas oglądania zwykłych zdjęć ludzi. Badania obejmowały łącznie ponad 1800 uczestników. Wynika z nich, że w percepcji scen przedstawiających ludzi nie występują znaczne różnice w sposobie ich eksploracji pomiędzy kobietami i mężczyznami.
} 
prezentowane na pasku. To, jak są ubrani eksperci, zwróciło uwagę wzrokową 31 uczestników badań. Osobami, które w największym stopniu skupiały uwagę badanych, co przejawiało się największą liczbą fiksacji na ich twarzach, byli eksperci oznaczeni symbolami EKSP1 i EKSP4. W przypadku EKSP1 wytłumaczeniem może być efekt pierwszeństwa, a w drugim przypadku widoczne emblematy eksperckości: tytuł naukowy i profesorska toga. Większość badanych właściwie wskazało obszar tematyczny przedstawionego im materiału, choć określało go szeroko jako grę polityczną dominujących partii bez zawężenia do wyborów samorządowych. Większe problemy wystąpiły przy wymienieniu z pamięci nazwisk ekspertów, badani najczęściej podawali dwa nazwiska, a tylko 4 uczestników badań zapamiętało nazwiska 7 na 9 wypowiadających się ekspertów. Jako zapamiętanych ekspertów badani wskazywali polityków, choć tutaj percepcja badanych skupiała się na osi podziałów politycznych, na przykład wśród wymienionych ekspertów był Jarosław Kaczyński, mimo że nie wypowiadał się w przedstawionym materiale filmowym. Większość badanych stwierdziła, że wypowiedzi ekspertów były niemerytoryczne, lub miała problemy z ich oceną, a jako wiarygodnych ekspertów wskazywali naukowców, wyróżniających się nie tylko tytułem, ale również emblematami - na przykład profesorską togą. Komunikaty prezentowane uczestnikom badań miały charakter multimodalny; odbiór przekazu był także uwarunkowany ich treścią wizualną, którą stanowiło między innymi ubranie osób wypowiadających się lub wyświetlona na pasku etykieta. Należy jednak podkreślić, iż większość respondentów oceniających komentarze ekspertów jako niemerytoryczne w pewnym sensie potwierdza hipotezę Toma Nicholsa (2017) o schyłku ekspertyzy i eksperckości. Z naszych badań wynika jeszcze jeden wniosek, a mianowicie: to mężczyźni byli bardziej uważni zarówno pod względem werbalnych, jak i pozawerbalnych przekazów zawartych w obejrzanym filmie, a zatem płeć może mieć wpływ na percepcję wypowiedzi eksperckich. Wnioski te wymagają jednak bardziej pogłębionych badań w przyszłości. Na koniec należy również podkreślić, że w kolejnych badaniach konieczne będzie uwzględnienie takich zmiennych, jak zainteresowanie polityką (tematyką komentowaną przez ekspertów) czy też ich znajomość.

\section{Bibliografia}

Basil M.D. (1994a). Multiple resource theory, I: Application to television viewing. „Communication Research", 21(2), s. 177-208.

Basil M.D. (1994b). Multiple resource theory, II: Empirical examination of modality - specific attention to television scenes. „Communication Research”, 21(2), s. 208-232.

Baudrillard J. (2006). Społeczeństwo konsumpcyjne. Jego mity i struktury. Warszawa: Wydawnictwo Sic!

Bauman Z. (1995). Wieloznaczność nowoczesna. Nowoczesność wieloznaczna. Warszawa: Polity Press.

Bauman Z. (2007). Płynne czasy: życie w epoce niepewności. Warszawa: Wydawnictwo Sic! 
Beck U. (2002). Społeczeństwo ryzyka. W drodze do innej nowoczesności. Warszawa: Wydawnictwo Naukowe Scholar.

Bergkamp L. (2017). The Concept of Risk Society as a Model for Risk Regulation - Its Hidden and Not So Hidden Ambitions, Side Effects, and Risks. „Journal of Risk Research", 20(10), s. $1275-1291$.

Boehm G., Mitchell W.J.T. (2009). Pictorial versus Iconic Turn: Two Letter. „Culture, Theory and Critique", 2, s. 103-121.

Bourdieu P. (2005). Dystynkcja. Społeczna krytyka władzy sądzenia. Warszawa: Wydawnictwo Naukowe Scholar.

Bourdieu P. (2011). O telewizji. Panowanie dziennikarstwa. Warszawa: Wydawnictwo Naukowe PWN.

Bucher H.J. (2015). Rozumienie multimodalne lub recepcja jako interakcja [w:] R. Opiłowski, J. Jarosz, P. Staniewski (red.), Lingwistyka mediów. Antologia tłumaczeń. Wrocław-Dresden: Wydawnictwo ATUT / Neisse Verlag.

Cialdini R.B. (2018). Wywieranie wpływu na ludzi. Teoria i praktyka. Sopot: Gdańskie Wydawnictwo Psychologiczne.

Eisenbarth H., Alpers W. (2011). Happy Mouth and Sad Eyes: Scanning Emotional Facial Expressions. „Emotion', 11(4), s. 860-865.

Foucault M. (1998). Nadzorować i karać. Narodziny więzienia. Warszawa: Fundacja Aletheia.

Francuz P., Cwalina W. (1999). Zapamiętywanie treści telewizyjnych programów informacyjnych [w:] P. Francuz (red.), Psychologiczne aspekty odbioru telewizji. Lublin: TN KUL.

Frutos-Pascual M., Garcia-Zapirain B. (2015). Assessing Visual Attention Using Eye Tracking Sensors in Intelligent Cognitive Therapies Based on Serious Games. „Sensors”, 15(5), s. 11092-11117.

Goćkowski J. (1998). Autorytet [w:] Z. Bokszański, A. Kojder (red.), Encyklopedia socjologii, t. 1: A-J. Warszawa: Oficyna Naukowa.

Godzic W. (2007). Znani z tego, że są znani. Celebryci w kulturze tabloidów. Warszawa: Wydawnictwa Akademickie i Profesjonalne.

Hessels R.S., Niehorster D.C., Nyström M., Andersson R., Hooge I.T.C. (2018). Is the Eye-Movement Field Confused about Fixations and Saccades? A Survey among 124 Researchers. „Royal Society Open Science", 5(8), 180502, s. 1-7.

Hofman I., Kępa-Figura D. (red.). (2018). Wspótczesne media - media multimodalne, t. 1: Zagadnienia ogólne i teoretyczne. Multimodalność mediów drukowanych. Lublin: Wydawnictwo UMCS.

Iedema R. (2013). Multimodalna analiza dyskursu: Resemiotyzacja na potrzeby dyskursów u̇̇ytkowych [w:] A. Duszak, G. Kowalski (red.), Systemowo-funkcjonalna analiza dyskursu. Kraków: Universitas.

Jenks Ch. (1995). The Centrality of the Eye in Western Culture: An Introduction [w]: Ch. Jenks (red.), Visual Culture. London: Routledge.

Jewitt C., van Leeuwen T. (2013). Handbook of Visual Analysis. London: Sage.

Katz E., Lazarsfeld P.F. (1955). Personal Influence: The Part Played by People in the Flow of Mass Communication. New York: Free Press.

Kenrick D.T., Neuberg S.L., Cialdini R.B. (red.). (2002). Psychologia społeczna. Gdańsk: Gdańskie Wydawnictwo Psychologiczne.

Kurczewska J. (1997). Technokraci i ich świat społeczny. Warszawa: IFiS PAN.

Luhmann N. (1997). Die Gesellschaft der Gesellschaft. Frankfurt am Main: Suhrkamp.

McLuhan M. (2004). Zrozumieć media. Przedłużenia człowieka. Warszawa: Wydawnictwa Naukowo-Techniczne. 
Min X., Zhai G., Gu K. (2015). Visual Attention on Human Face: Visual Communications and Image Processing (VCIP). Singapore, s. 1-4.

Mucha J. (2009). Uspołeczniona racjonalność technologiczna. Naukowcy z AGH wobec cywilizacyjnych wyzwań i zagrożeń. Warszawa: Wydawnictwo IFiS PAN.

Mythen G. (2018). Thinking with Ulrich Beck: Security, Terrorism and Transformation. „Journal of Risk Research", 21(1), s. 17-28.

Nęcka E., Orzechowski J., Szymura B. (2008). Psychologia poznawcza. Warszawa: Wydawnictwo Naukowe PWN.

Nichols T. (2017). The Death of Expertise: The Campaign against Established Knowledge and Why It Matters. Oxford: Hardcover.

Olechnicki K. (2016). Uwagi o kulturze wizualnej w ujęciu socjologiczno-antropologicznym. „Dyskurs”, 16. Wrocław: ASP.

Parsons T. (1964). Social Structure and Personality. New York: Free Press of Glencoe.

Porębski M. (1972). Ikonosfera. Warszawa: Państwowy Instytut Wydawniczy.

Rose G. (2012). Visual Methodologies: An Introduction to Researching with Visual Materials. London: Sage.

Rose G. (2015). Interpretacja materiałów wizualnych. Krytyczna metodologia badań nad wizualnością. Warszawa: Wydawnictwo Naukowe PWN.

Sartori G. (2007). Homo videns. Telewizja i postmyślenie. Warszawa: Wydawnictwa Uniwersytetu Warszawskiego.

Swoles J. (1990). Genre Analysis: English in Academic and Research Settings. Cambridge: Cambridge Applied Linguistics.

Wojciszke B. (2002). Człowiek wśród ludzi. Zarys psychologii społecznej. Warszawa: Wydawnictwo Naukowe Scholar.

Zakrzewska-Manterys E. (2006). Życiowe tsunami: obligatoryjność refleksyjności. „Societas/ Communitas", 1, s. 2-6. 
